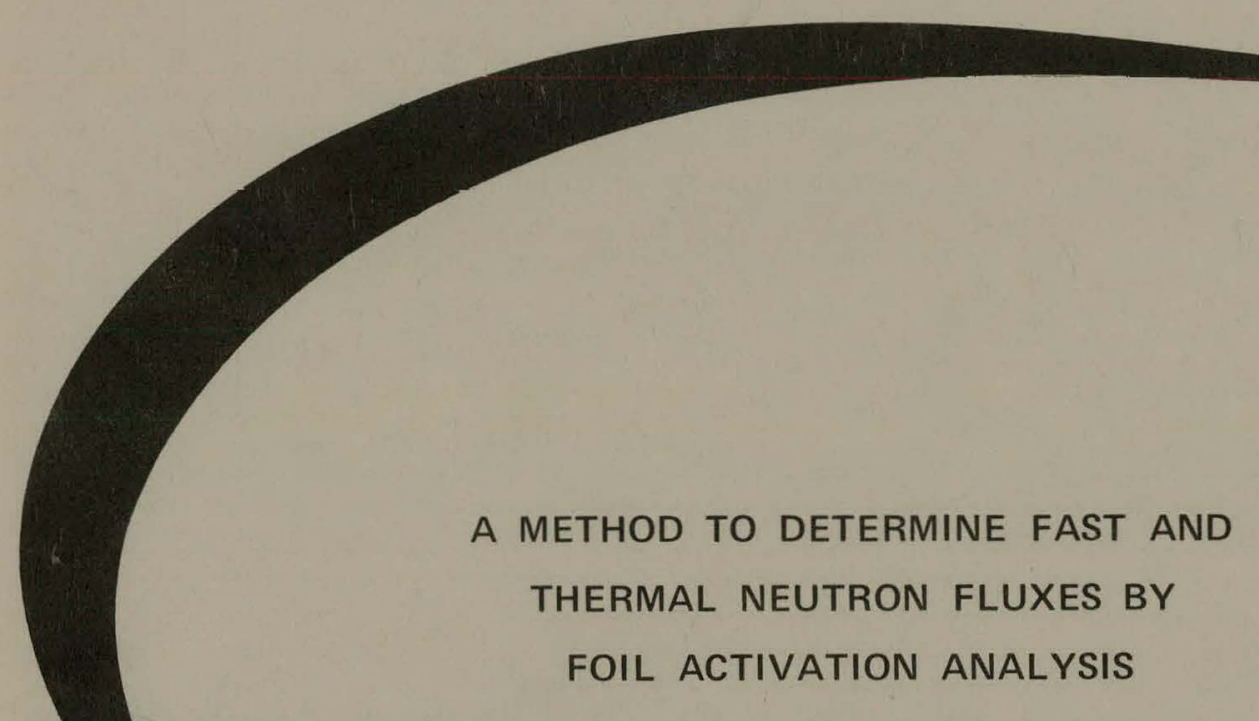

Richard L. Murri

Dennis G. Vasilik

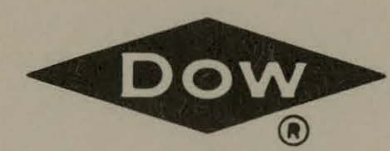

THE DOW CHEMICAL COMPANY

ROCKY FLATS DIVISION

P. O. BOX 888

GOLDEN, COLORADO 80401

U.S. ATOMIC ENERGY COMMISSION CONTRACT AT(29-1)-1106 


\section{DISCLAIMER}

This report was prepared as an account of work sponsored by an agency of the United States Government. Neither the United States Government nor any agency Thereof, nor any of their employees, makes any warranty, express or implied, or assumes any legal liability or responsibility for the accuracy, completeness, or usefulness of any information, apparatus, product, or process disclosed, or represents that its use would not infringe privately owned rights. Reference herein to any specific commercial product, process, or service by trade name, trademark, manufacturer, or otherwise does not necessarily constitute or imply its endorsement, recommendation, or favoring by the United States Government or any agency thereof. The views and opinions of authors expressed herein do not necessarily state or reflect those of the United States Government or any agency thereof. 


\section{DISCLAIMER}

Portions of this document may be illegible in electronic image products. Images are produced from the best available original document. 


\section{LEGAL NOTICE}

This report was prepared as an account of work sponsored by the United States Government. Neither the United States nor the United States Atomic Energy Commission, nor any of their employees, nor any of their contractors, subcontractors, or their employees, makes any warranty, expressed or implied, or assumes any legal liability or responsibility for the accuracy, completeness or usefulness of any information, apparatus, product or process disclosed, or represents that its use would not infringe privately owned rights.

Printed in the United States of America

Available from the

National Technical Information Service

U. S. Department of Commerce

Springfield, Virginia 22151

Price: Printed Copy $\$ 3.00$ : Microfiche $\$ 0.65$ 


\title{
A METHOD TO DETERMINE FAST AND THERMAL NEUTRON FLUXES BY FOIL ACTIVATION ANALYSIS
}

\author{
Richard L. Murri
}

Dennis G. Vasilik

LEGAL NOTICE

This report was prepared as an account of work sponsored by the United States Government. Neither the United States nor the United States Atomic Energy Commission, nor any of their employees, nor any of their contractors, subcontractors, or their employees, makes any warranty, express or implied, or assumes any legal liability or responsibility for the accuracy, completeness or usefulness of any information, apparatus, product or process disclosed, or represents that its use would not infringe privatelv owned rights.

\author{
THE DOW CHEMICAL COMPANY \\ ROCKY FLATS DIVISION \\ P. O. BOX 888 \\ GOLDEN, COLORADO 80401 \\ Prepared under Contract AT(29-1)-1106 \\ for the \\ Albuquerque Operations Office \\ U. S. Atomic Energy Commission
}


RFP-1466 


\section{O N T E N T S}

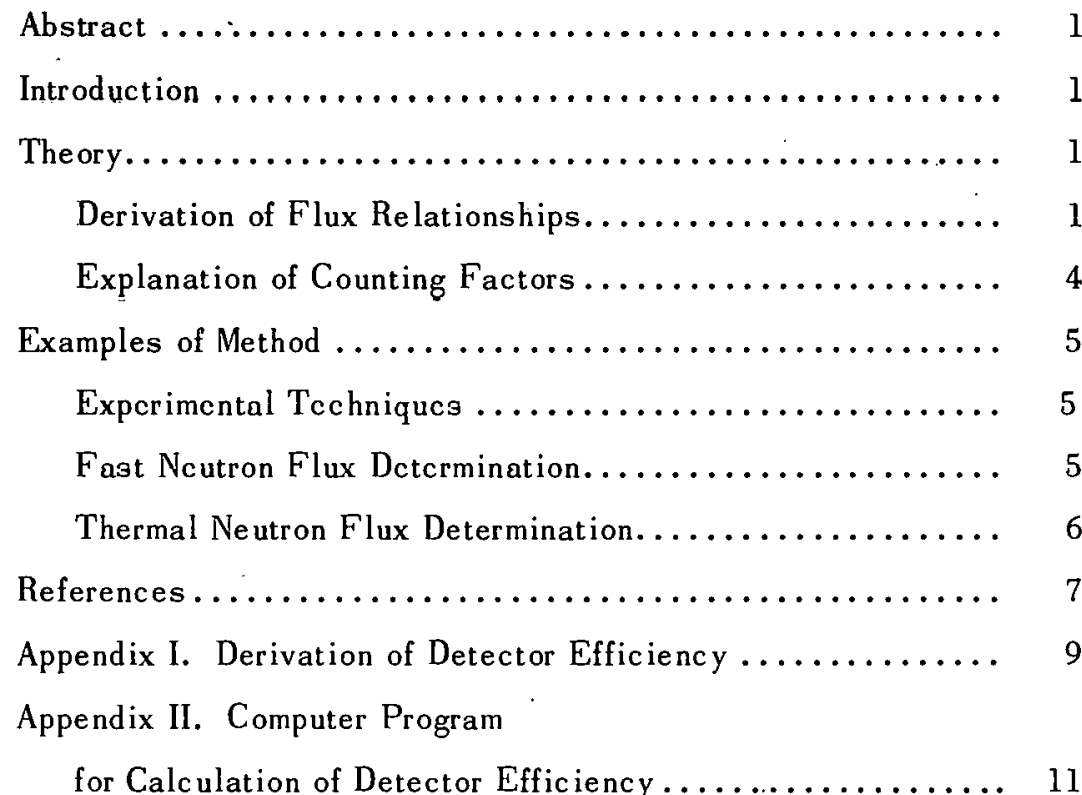




\title{
A METHOD TO DETERMINE FAST AND THERMAL NEUTRON FLUXES BY FOIL ACTIVATION ANALYSIS
}

\author{
Richard L. Murri and Dennis G. Vasilik
}

\begin{abstract}
A general method of foil activation analysis for measuring neutron fluxes is presented with a complete derivation of the mathematical expressions used. Although the method is not new, descriptions of the theory, experimental procedures, and the constants and parameters used in the analys is are widely scattered in the literature. This report compiles this information for easy reference. Detailed examples us ing copper foil activation for measuring fast neutron fluxes and indium foil activation for measuring thermal neutron fluxes are given.
\end{abstract}

\section{INTRODUCTION}

As part of a project to develop neutron radiography using a ne utron generator, it was necessary to measure the fast neutron output of the generator and the thermal ne utron fluxes produced in a moderator surrounding the generator. A method of foil activation analysis was chosen to determine the desired fluxes.

Before this technique could be applied it was necessary to search the literature extensively to find the theory and the values for the experimental quantities associated with the method. In many case our experimental conditions were different from those reported in the literature and it was difficult to obtain the correct values. This report compiles all the information necessary to apply this technique to a wide variety of experimental conditions.

The complete derivation of the mathematical theory is given. The formulae obtained relate the neutron flux to the number of counts registered by the counting system. The expression also takes into account all the experimental conditions including irradiation time, transfer time, counting time, area and thickness of foil, type of foil, and various counting factors. These factors are discussed and an explanation is given as to how the values for each are obtained.

One of the more difficult values to obtain is the detector efficiency. This factor combines the geometry factor and the efficiency of the detcctor to absorb radiation of a particular energy. An expression for this factor is derived in $\Lambda$ ppendix I and a computer program used to calculate it is given in Appendix II.
Copper foil was used to determine the fast neutron flux and indium foil was used to determine the thermal flux. An example of each type of determination is discussed in detail.

\section{THEORY}

\section{Derivation of Flux Relationships:}

It is possible to measure the intensity of a neutron flux by taking advantage of certain neutron absorption reactions which lead to the formation of radioisotopes whose activity can be determined by gamma counting. The activity of an irradiated sample is directly related to the neutron flux. In deriving this relationship, the following assumptions are madè:

1. The neutron source is isotropic.

2. Multiple interactions between neutrons and nuclei are negligible.

A thin foil of known physical and nuclear properties is irradiated by neutrons for a given time $t_{0}$. The foil is then removed from the flux and transferred to a counter where its activity is measured. Figure 1 shows the time sequence for this procedure.

The rate $R$ per unit area of foil at which neutrons in the beam interact with nuclei in the foil in a small thickness $d x$ at the position $x$ (measured from the front face of the foil) is given by

$$
\mathrm{dR}=\phi(x) \mathrm{n}_{\mathrm{t}} \sigma_{\mathrm{t}} \mathrm{dx}
$$

where $n_{\mathrm{t}}$ is the total number of nuclei per unit volume, $\sigma_{t}$ is the total neutron cross section, and $\phi(x)$ is the neutron flux in neutrons $/ \mathrm{cm}^{2} / \mathrm{sec}$. The flux $\phi$ is not constant throughout the foil but is equal to the incident flux minus the rate at which neutrons have been removed from the beam by interactions with nucle $i$ in a thickness $x$ of the foil. 'That is,

$$
\phi(\mathbf{x})=\phi_{0}-\mathrm{R}(\mathbf{x})
$$



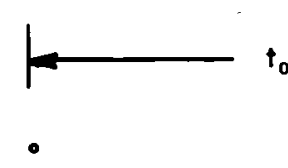

$\uparrow$

Start

activation

of foil

Number of

radioactive atoms

present gt given

times $t_{1}$

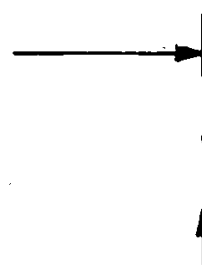

End

activation,

Initiate

transfer

$\uparrow$

$N_{0}$ $t_{2}$

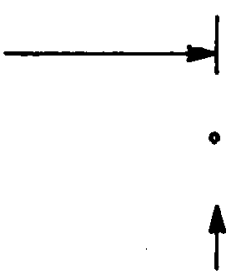

End

transfer,

Start

count

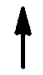

$N_{1}$
End

count

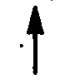

$\mathrm{N}_{2}$

Figure 1. Activation Ana lysis Sequence.

Substituting Equation 2 into Equation 1 gives

$$
\mathrm{dR}=\left(\phi_{0}-\mathrm{R}\right)_{\mathrm{n}_{\mathrm{t}}} \sigma_{\mathrm{t}} \mathrm{dx}
$$

or

$$
\stackrel{d R}{\phi_{0}-R}-{ }^{i n}{ }^{\sigma} t^{d x}
$$

Integrating over the thickness of the foil,

$$
\ln \left(\phi_{n}-R\right)=-n_{t} \sigma_{t} x+L .
$$

At $x=0, R=0$, so $C=\ln \phi_{0}$ and the above equation becomes

$$
\ln \left(\phi_{0}-R\right)-\ln \phi_{0}=-n_{t^{U}} t^{x} .
$$

This can then be rewritten as

$$
\mathrm{R}=\dot{\phi}_{0}\left(1-\mathrm{e}^{-\mathrm{n}_{\mathrm{t}} \sigma_{\mathrm{t}} \mathrm{x}}\right)
$$

'The total rate at which neutrons interact with the nuclei in the foil is thus

$$
R A=\phi_{0} A\left(1-e^{-n_{t} \sigma_{t} x}\right),
$$

where $A$ is the area of the foil. Equation 3 gives the total interaction rate which includes scattering events and many types of absorption reactions. The activity in the foil that is actually measured is produced by one particular nuclear reaction. Thus, it is the rate at which this particular rcaction is occurring, not tho total rate as given in Equation 3, that must be related to the activity in the foll.

The parlicular rate is obtained by mult iplying the total rate (Equation 3 ) by the relative probability that the des ired reastion will oscur. This re lative proh= ability is the ratio of the matruscopic cruss sectiun $\Sigma_{\mathrm{p}}$ for the particular reaction to the total macroscopic cross section $\Sigma_{t}$. Thus, the rate at which particular nuclei are being aulivaled in a specifie way is given by

$$
R_{p} A=\phi_{0} A\left(1-e^{\left.-n_{t} \sigma_{t} x\right) \frac{\Sigma_{p}}{\Sigma_{t}} .}\right.
$$

where the subscript $p$ refers to the particular reaction of interest.

Since $\Sigma=n \sigma$, the above equation can be written as

$$
\mathrm{R}_{\mathrm{p}} \mathrm{A}=\phi_{0} \mathrm{~A}\left(\mathrm{l}-\mathrm{e}^{-\mathrm{n}_{\mathrm{t}} \sigma_{\mathrm{t}} \mathrm{x}}\right) \frac{{ }_{\mathrm{n}_{\mathrm{p}} \sigma_{\mathrm{p}}}}{\mathrm{n}_{\mathrm{t}} \sigma_{\mathrm{t}}} .
$$


During activation, the rate of change of the number $\mathrm{N}$ of activated nuclei is equal to the rate at which they are produced minus the rate at which they decay. Thus,

$$
\frac{d N}{d t}=R A-\lambda N
$$

where $\lambda$ is the decay constant.

This can be rearranged to the form

$$
\frac{\mathrm{dN}}{\left(\frac{\mathrm{RA}}{\lambda}-\mathrm{N}\right)}=\lambda \mathrm{dt}
$$

Integrating,

$$
\ln \left(\frac{\mathrm{M} \Lambda}{\lambda}-\mathrm{N}\right)=-\lambda \mathrm{t}+\mathrm{C}
$$

At $t=0, N=0$, so $C=\ln R A / \lambda$ and then this equation can be written as

$$
\ln \left(\frac{\frac{\mathrm{RA}}{\lambda}-\mathrm{N}}{\frac{\mathrm{RA}}{\lambda}}\right)=-\lambda \mathrm{t},
$$

or

$$
\mathrm{N}=\frac{\mathrm{RA}}{\lambda}\left(1-\mathrm{e}^{-\lambda \mathrm{t}}\right)
$$

If we let $N=N_{0}$ at the end of irradiation $\left(t=t_{0}\right)$, then the above equation becomes

$$
\mathrm{N}_{0}=\frac{\mathrm{RA}}{\lambda}\left(1-\mathrm{e}^{-\lambda \mathrm{t}_{0}}\right) .
$$

During transfer from the neutron irradiation position to the gamma counter, the rate of decay is

$$
\frac{d N}{d t}=-\lambda N,
$$

where $t=0$ is now defined to be at the start of transfer. Integrating, this becomes

$$
\ln N=-\lambda t+C .
$$

At $\mathrm{t}=0, \mathrm{~N}=\mathrm{N}_{0}$, so $\mathrm{C}=\ln \mathrm{N}_{0}$ and

$$
\ln \frac{N}{N_{0}}=-\lambda t,
$$

or

$$
\mathrm{N}=\mathrm{N}_{\mathbf{0}} \mathrm{e}^{-\lambda \mathrm{t}} \text {. }
$$

At $\mathrm{t}=\mathrm{t}_{1}, \mathrm{~N}=\mathrm{N}_{1}$; thus,

$$
N_{1}=N_{0} e^{-\lambda t_{1}} .
$$

Similarly, during counting, the rate of decay is $d N / d t=-\lambda N$ where $t=0$ is now defined to be at the start of counting. Using the conditions that at $t=0$, $\mathrm{N}=\mathrm{N}_{1}$ and at $\mathbf{t}=\mathrm{t}_{2}, \mathrm{~N}=\mathrm{N}_{2}$ the result is

$$
\mathrm{N}_{2}=\mathrm{N}_{2} \mathrm{e}^{-\lambda \mathrm{t}_{2}}
$$

'The number of atoms which decay during time $t_{2}$ is just $N_{1}-N_{z}$. Denoting this by $N_{T}$,

$$
\mathrm{N}_{\mathrm{T}}=\mathrm{N}_{1}-\mathrm{N}_{2}=\mathrm{N}_{1}\left(1-\mathrm{e}^{-\lambda \mathrm{t}_{2}}\right) \text {. }
$$

Substituting for $N_{1}$ and $N_{0}$ using (5), (6), and (7) results in

$$
\mathrm{N}_{\mathrm{T}}=\frac{\mathrm{R}_{\mathrm{p}} \mathrm{A}}{\lambda}\left(1-\mathrm{e}^{-\lambda \mathrm{t}_{0}}\right) \mathrm{e}^{-\lambda \mathrm{t}_{1}}\left(1-\mathrm{e}^{-\lambda \mathrm{t}_{2}}\right) .
$$

Using (4) this becomes

$N_{T}=\frac{\phi_{0} A n_{p} \sigma_{p}\left(1-e^{-n_{t} \sigma_{t} x}\right)}{n_{t} \sigma_{t} \lambda}\left(1-e^{-\lambda t_{0}}\right) e^{-\lambda t_{1}}\left(1-e^{-\lambda t_{2}}\right)$.

Equation (8) is an expression for the true number of atoms which decay during the counting period $t_{2}$.

$\mathrm{N}_{\mathrm{T}}$ is also related to the number of counts $\mathrm{C}$ obtained by counting the activated foil. When gamma counting is used in the analysis, the area of a particular photopeak is determined from ithe gamma spectrum. This area $(C)$ is related to $\mathrm{N}_{\mathrm{T}}$ by correcting for photopeak efficiency $P$, branching ratio $\epsilon$, absorption correction factor $a$, and detector efficiency $q$. These factors are explained in the next section. The relation between $\mathrm{N}_{\mathrm{T}}$ and $\mathrm{C}$ is thus

$$
\mathrm{N}_{\mathrm{T}}=\mathrm{C} / \mathrm{P} \text { eaq. }
$$


Substituting in Equation (8) one obtains

$\frac{C}{P \epsilon a q}=\frac{\phi_{u} A n_{p} \sigma_{p}}{n_{t} \sigma_{t} \lambda}\left(1-e^{-\sigma_{t} n_{t} x}\right)\left(1-e^{-\lambda t_{0}}\right) e^{-\lambda t_{1}}\left(1-e^{-\lambda t_{2}}\right)$,

or

$\phi_{0}=\frac{n_{\mathrm{t}} \sigma_{\mathrm{t}} \lambda \mathrm{C}}{\operatorname{PeaqAn}_{\mathrm{p}} \dot{\sigma}_{\mathrm{p}}\left(1-\mathrm{e}^{-\sigma_{\mathrm{t}} \mathrm{n}_{\mathrm{t}} \mathrm{x}}\right)\left(1-\mathrm{e}^{-\lambda \mathrm{t}_{\mathrm{o}}}\right) \mathrm{e}^{-\lambda \mathrm{t}_{1}}\left(1-\mathrm{e}^{-\lambda \mathrm{t}_{2}}\right)}$

This expression thus gives the neutron flux in neutrons $/ \mathrm{cm}^{2}$-sec as a function of the number of counts in a certain photopeak measured during counting time $t_{2}$.

The total neutron output of the source in neutrons/ $\sec$ is given by

$$
\phi_{\mathrm{t}}=4 \pi \mathrm{R}^{2} \phi_{\mathrm{n}}
$$

where $R$ is the distance from the source to the foil.

\section{Explanation of Counting Factors:}

As given previously, the relationship between $\mathrm{N}_{\mathrm{T}}$ and $\mathrm{C}$ is $\mathrm{PN}^{\prime} \mathrm{Y}=\mathrm{C} /$ 'Peuq.

$P$ is the photopeak efficiency or sometimes called the peak-to-total ratio. A gamma ray may interact with the detector in three different ways: (1) photoelectric effect, (2) Compton effect, or (3) pair production. The $P$ is the ratio of the number of gammas of a certain energy interacting by the photoelectric effect to the number of gammas of the same energy interacting by all threc proecsies.

$P$ is dependent on the energy of the gamma ray and the size of the detector. 'I'he factor can be experimentally measured or obtained from published data.'

$\epsilon$ is the branching ratio. This is the number of gamma rays of a certain energy emitted per decay of the activated nuclide. This factor is obtained by studying the decay scheme of the nuclide of interest.

$a$ is the gamma-ray absorption correction factor. It is composed of two parts. One part corrects for self absorption in the foil and the other corrects for absorption in an absorber. Both are calculated in the same way. If an absorber is present between the foil and the detector, it will interact with some of the gamma rays coming from the foil, preventing them from reaching the detector. 'Ihe gamma-ray absorption factor, $a$, is computed by determining the ratio of the intensity of gammas, of a given energy passing through the' absorber lo the intensity of the gammas of the given energy incident on the absorber. This is expressed as ${ }^{2}$

$$
\mathrm{a}=\frac{\mathrm{I}}{\mathrm{I}_{\mathrm{o}}}=\mathrm{B}_{\mathrm{f}} \mathrm{B}_{\mathrm{a}} \mathrm{e}^{\left(-\mu_{\mathrm{f}} \rho_{\mathrm{f}} \Delta \xi_{\mathrm{f}}-\mu_{\mathrm{a}} \rho_{\mathrm{a}} \Delta \xi_{\mathrm{a}}\right)}
$$

where $B$ is the dose buildup factor, $\mu$ is the mass attenuation coefficient, $\rho$ is the density of the absorber and $\Delta \xi$ is the absorber thickness. The subscripts $f$ and a represent the foil and absurber respectively. Since we are concerned with only a certain energy gamma ray passing through the absorber, the dose buildup factors $B_{f}=B_{a}=1.0 .^{2}$

$q$ is the detector efficiency. It is a measure of the ability of the detector to detect the radiation coming from the radioactive source. It is a combination of a geomctry factor and the probability that a certain energy photon will be adsorbed in the detector. For a thin disk source of radius $\mathrm{R}$ placed at a height $\mathrm{II}_{0}$ above a NaI(T1) cryatal of radius $r_{0}$, and thickuc $s L_{0}$; thi detector efficiency is given by ${ }^{1}$

$$
\begin{aligned}
\mathrm{q}= & \frac{1}{\pi \mathrm{R}^{2}} \int_{0}^{\mathrm{R}} \mathrm{xdx} \int_{-\pi / 2}^{\pi / 2} \mathrm{~d} \phi\left\{\int_{0}^{\theta_{1}}\left(1-\mathrm{e}^{-\tau \cdot \mathrm{t}_{0} / \cos \theta}\right) \sin \theta \mathrm{d} \theta\right. \\
& \left.\left.+\int_{\theta_{1}}^{\theta_{2}}\left[1-\mathrm{e}^{-\tau \cdot(\chi} / \sin \theta-\mathrm{h}_{0} / \cos \theta\right)\right] \sin \theta \mathrm{d} \theta\right\}
\end{aligned}
$$

whèrë $\chi=-x \sin \phi+\sqrt{x^{2} \sin ^{2} \phi+r_{0}^{2}-x^{2}}$

$$
\theta_{1}=\tan ^{-1} \frac{x}{t_{0}+h_{0}}
$$

$$
\theta_{2}=\tan ^{-1} \frac{x}{h_{0}}
$$

$\tau=$ absorption coefficient for $\mathrm{NaI}$ (dependent on photon energy). 
For a disk thick enough that its finite thickness must be taken into account and the same conditions as above, the detector efficiency is

$$
\begin{aligned}
\mathrm{q}= & \frac{1}{\pi \mathrm{R}^{2} \mathrm{t}} \int_{0}^{\mathrm{t}} \mathrm{dy} \int_{0}^{\mathrm{R}} \mathrm{xdx} \int_{-\pi / 2}^{\pi / 2} \mathrm{~d} \phi \\
& \left\{\int _ { 0 } ^ { \theta _ { 1 } } \left(1-\mathrm{e}^{\left.-\tau \cdot \mathrm{t}_{0} / \cos \theta\right) \sin \theta \mathrm{d} \theta}\right.\right. \\
& +\int_{\theta_{1}}^{\theta_{2}}\left[1-\mathrm{e}^{\left.\left.-\tau \cdot\left(\chi / \sin \theta-\mathrm{h}_{0} / \cos \theta\right)\right] \sin \theta \mathrm{d} \theta\right\}}\right.
\end{aligned}
$$

where $t$ is the thickness of the source.

The derivation of the above equations is given in Appendix I. These equations and many efficiencies for various crystal sizes and gamma energies are given in reference 1 . For cases not listed in reference 1 the equations must be numerically integrated. The efficiency for the particular case described in the following section to illustrate the method was not given, therefore a computer program was written using the above equation to calculate q. This program is included in Appendix II. It was written in FORTRAN IV for use on Computer Sharing Services Time Sharing System.

\section{EXAMPLES OF METHOD}

\section{Experimental Techniques:}

The neutron source used in these experiments is a Kaman Nuclear Model A-711 Sealed-Tube Neutron Generator with a rated output of 14-MeV neutrons of $10^{11} \mathrm{n} / \mathrm{sec}$. The head of the generator is placed in a 30-inch-diameter cylindrical graphite assembly which moderates and collimates the neutrons.

The flux at a given position in the neutron beam is determined by irradiating a metal foil at that position and then measuring the activity of the foil by gamma counting.

The counting apparatus used for these measurements is shown in Figure 2. The counting system was calibrated by first taking a complete gamma spectrum of the radioactive foil and then locating the photopeak of

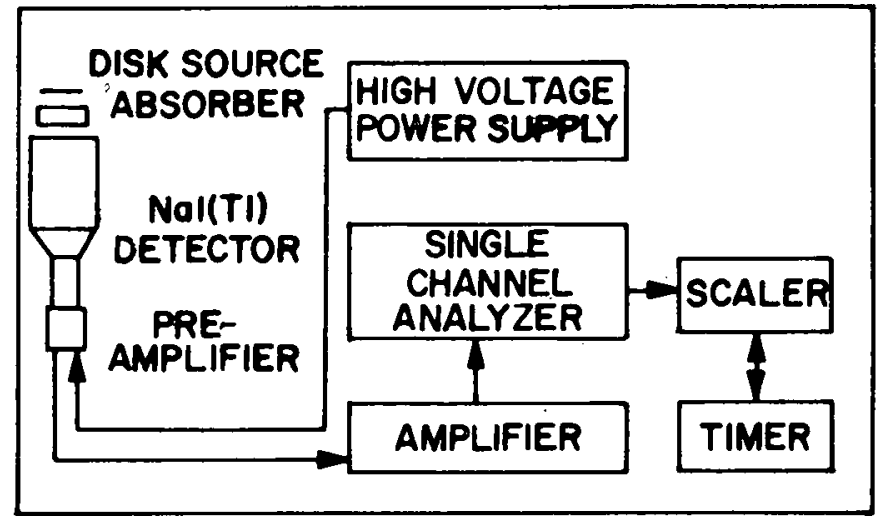

Figure 2. Gamma Counting System.

interest. The window of the single channel analyzer was then set to accept just this photopeak. The counting sequence included a count of the foil and then a background count. $C$, as given in Equation (9), is the foil count minus the background count.

The fast and thermal neutron fluxes are measured separately and will be discussed separately in the following sections.

\section{Fast Neutron Flux Determination:}

The fast neutron flux is determined by activating and counting a copper foil. For the purposes of this paper "fast" neutrons will be taken to mean approximately 14-MeV neutrons.

Neutron activation of copper leads to the following reactions

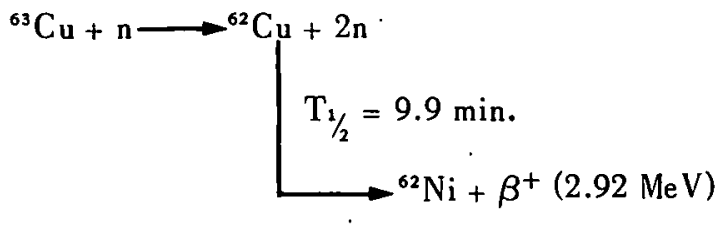

The activated copper foil is sandwiched between two $3 / 8$-inch-thick disks which annihilate the positrons causing the emission of two $0.51 \mathrm{l}-\mathrm{MeV}$ gammas per annihilation. These gammas are counted to measure the activity. The absorber thickness was chosen to ronform to the "Texas Convention."

I'able I gives the essential physical and nuclear properties of the copper foil used in the analysis. 
Table I. Physical and Nuclear Properties of Copper Foil.

\begin{tabular}{|c|c|}
\hline Thickness of foil & $x=0.0254 \mathrm{~cm}$ \\
\hline Area of foil & A $=5.0671 \mathrm{~cm}^{2}$ \\
\hline Density of copper & $\rho=8.96 \mathrm{~g} / \mathrm{cc}$ \\
\hline Is ot opic abundance of ${ }^{63} \mathrm{Cu}$ & 0.6909 \\
\hline Average atomic woight of $\mathrm{Cu}$ & $63.54 \mathrm{amu}$ \\
\hline $\begin{array}{l}\text { Half life of }{ }^{62} \mathrm{Cu} \text { decay } \\
\beta^{+} \text {emission per }{ }^{62} \mathrm{Cu} \text { decay }\end{array}$ & $\begin{aligned} \mathrm{T}_{1 / 2}= & 9.9 \mathrm{~min} . \\
& 0.97\end{aligned}$ \\
\hline $\begin{array}{l}\text { Cross section for }(n, 2 n) \text { reaction } \\
\text { Number of }{ }^{63} \mathrm{Cu} \text { nuclei per unit vol. } \\
\text { Decay constant for }{ }^{62} \mathrm{Cu}\end{array}$ & $\begin{aligned} \sigma_{\mathrm{p}} & =530 \mathrm{mb}^{\mathrm{a}} \\
\mathrm{n}_{\mathrm{p}} & =5.8675 \times 10^{22} \mathrm{~cm}^{-3} \\
\lambda & =0.0011669 \mathrm{sec}^{-1}\end{aligned}$ \\
\hline Number of Cu nuclei per unit vol. & $\mathrm{n}_{\mathrm{t}}=8.4925 \times 10^{22} \mathrm{~cm}^{-3}$ \\
\hline Total cross section & $\sigma_{\mathrm{t}}=2.88 \mathrm{~b}^{\mathrm{a}}$ \\
\hline
\end{tabular}

aurrey D. Goldberg, et al., Neutron Cross Sections, BNL 325, 2nd ed., Supp. No. 2, Vol. II-A, Fobruary 1966.

The cross section is very energy dependent and the energy of the neutrons depends on the angle at which they are emitted from the source. The value of $530 \mathrm{mb}$ is for 14.4-MeV neutrons which are emitted at an angle of $45^{\circ}$ from the accelerator beam.

The number of ${ }^{63} \mathrm{Cu}$ atoms per unit volume is calculated using the formula

$$
\mathrm{n}_{\mathrm{p}}=\frac{\mathrm{N}_{\mathrm{AV}} \cdot \rho \cdot \text { (Isotopic Abundance) }}{\text { Atomic Weight }}
$$

where $\mathrm{N}_{\mathrm{AV}}$ is Avugadio's number.

The counting factors for the fast neutron measurement are as follows: (1) Photopeak efficiency; for $0.511-\mathrm{MeV}$ gammas detected by a 3-inch diameter $\times$ 3-inch thick NaI(Tl) crystal, $\mathrm{P}=0.625$, $^{\prime}$ (2) Branching ratio; there are two $0.511-\mathrm{MeV}$ gammas emitted per positron annihilation and 0.97 positrons emitted per decay of ${ }^{62} \mathrm{Cu}$; thus $\epsilon=1.94$. (3) Absorption correction factor; for a Lucite absorber and for $0.511-\mathrm{MeV}$ gammas, $\mu=0.095 \mathrm{~cm}^{2} / \mathrm{g}$. The density of Lucite is $1.170 \mathrm{~g} / \mathrm{cm}^{2}$. The absorber completely surrounds the foil and thus the thickness used is the average thickness or $\Delta \xi=0.9525 \mathrm{~cm}$. For copper $\mu=0.084 \mathrm{~cm}^{2} / \mathrm{g}$, $\rho=8.96 \mathrm{~g} / \mathrm{cm}^{3}$ and the average thickness $\Delta \xi=0.0127 \mathrm{~cm}$ Using these parameters the absorption correction factor is

$\mathrm{a}=\exp (-0.084 \cdot 8.96 \cdot 0.0127-0.095 \cdot 1.176 \cdot 0.9525)$

$$
=0.8905 \text {. }
$$

(4) Detector efficiency; the copper foils used in this measurement are $2.54-\mathrm{cm}$ diameter and are sandwiched between $0.9525-\mathrm{cm}$-thick Lucite absorbers. This whole assembly is the source of $0.511 \mathrm{MeV}$ gammas. The source thickness is thus $1.905 \mathrm{~cm}$ and the source to detector distance is $2.0475 \mathrm{~cm}$. The absorption coefficient. ${ }^{1} \tau=0.32 \mathrm{~cm}^{-1}$. Using the computer program in Appendix II, the detector efficiency for the above arrangement was calculated to be $q=0.1075$.

The time intervals used for the fast neutron measirement are: irradiation time $t_{0}=2 \mathrm{~min}$., transfer time $t_{1}=2$ min., and counting time $t_{2}=2$ minutes.

Substituting all these values in equation (9) one obtains

$$
\phi_{0}=109.0812 \mathrm{C} \text {. }
$$

As a specific example, a copper foil was placed $30.48 \mathrm{~cm}$ from the source at an angle of $45^{\circ}$ from the beam. The irradiation time was 2 minutes, transfer time was 2 minules, and cuunling line was 2 minules. The count was 36,448 and the background showed 8625 counts. Thus, $\mathrm{C}=27,823$ and

$$
\phi_{0}=169.6812 .27,823=4.721 \times 10^{6} \mathrm{n} / \mathrm{cm}^{2} \text {-sec. }
$$

The total ne utron output is then

$$
\begin{aligned}
\phi_{t} & =4 \pi(30.48)^{2} .4 .721 \times 10^{\circ} \mathrm{n} / \mathrm{sec} . \\
& =5.51 \times 10^{10} \mathrm{n} / \mathrm{sec} .
\end{aligned}
$$

The error associated with this measurement is estimated to be $5 \%$.

\section{Thermal Neutron Flux Determination:}

The thermal flux is determined by activating and counting an indium foil. Neutron activation of the indium leads to the following reactions:

$$
{ }^{115} \mathrm{In}+\mathrm{n} \longrightarrow{ }^{110^{\mathrm{m}}} \mathrm{In} \longrightarrow{ }^{116} \mathrm{Sn}+\beta^{-1} \mathrm{~s}+\text { gammas. }
$$

In the decay of ${ }^{116} \mathrm{~S} n$ to the ground state a number of gammas are emitted. One of the most prominent is a 1.29-MeV gamma. The area of the 1.29-MeV photopeak is used to determine the activity of the indium foil.

'lo stop the betas from entering the crystal and interfering with the counting results, a Lucite absorber is 
placed between the indium foil and the detector. The thickness required to stop the $1-\mathrm{MeV}$ beta is approximately $0.381 \mathrm{~cm}$.

Table II gives the essential properties of the indium used in this analysis.

Table II. Physical and Nuclear Properties of Indium Foil.

\begin{tabular}{|c|c|}
\hline Thickness of foil & $x=0.0761 \mathrm{~cm}$ \\
\hline Area of foil & $A=4.7875 \mathrm{~cm}^{2}$ \\
\hline Density of indium & $\rho=7.31$ \\
\hline Isotopic abundance of ${ }^{115} \mathrm{In}$ & 0.9572 \\
\hline Average atomic weight of In & 114.82 \\
\hline Half life of ${ }^{116 \mathrm{~m}}$ In decay & $T_{1 / 2}=54 \mathrm{~min}$. \\
\hline Number of 1.29 gammas per ${ }^{116 \mathrm{~m}} \mathrm{In}$ decay & 0.81 \\
\hline Cross section for $(n, \gamma)$ reaction & $\sigma_{p}=157 b^{a}$ \\
\hline Number of ${ }^{115}$ In nuclei per unit vol. & $n_{p}=3.67 \times 10^{22} \mathrm{~cm}^{-3}$ \\
\hline Decay constant for ${ }^{116}$ In & $\lambda=0.000213934 \mathrm{sec}^{-1}$ \\
\hline Number of In nuclei per unit vol. & $n_{t}=3.83 \times 10^{22} \mathrm{~cm}^{-3}$ \\
\hline Cot.al cross section & $\sigma_{\mathrm{l}}=196 \mathrm{~h}^{\mathrm{a}}$ \\
\hline
\end{tabular}

a Murrey D. Goldberg et al., Neutron Cross Sections, BNL 325, 2nd ed., Supp. No. 2, Vol. II-B, August 1966.

The counting factors for the thermal neutron measurement are as follows: (1) Photopeak efficiency; for a 1.29-MeV gamma detected by a 3-inch-diameter $x$ 3-inch-thick $\mathrm{NaI}(\mathrm{Tl})$ crystal, $\mathrm{P}=0.355$. (2) Branching ratio; from the decay scheme of indium- $116 \mathrm{~m}$, the average number of $1.29-\mathrm{MeV}$ gammas produced per decay of the nucleus is 0.81 . Thus, $\epsilon=0.81$. (3) Absorption correction factor; for indium $\mu=0.052 \mathrm{~cm}^{2} / \mathrm{g}, \rho=7.31$ $\mathrm{g} / \mathrm{cm}^{3}$, and $\Delta \xi=0.381 \mathrm{~cm}$. Using these parameters the absorption correction factor is

$\mathrm{a}=\exp (-0.052 \cdot 7.31 \cdot 0.038-0.062 \cdot 1.176 \cdot 0.381)$

$$
=0.9587 \text {. }
$$

(4) Detector efficiency; the indium foils used in this measurement are $2.54 \mathrm{~cm}$ in diameter and are placed $3.0 \mathrm{~cm}$ from the 3 -inch-diameter $\times 3$-inch-thick NaI(Tl) crystal. For a 1.29-MeV gamma the absorption coefficient is $\tau=0.203 \mathrm{~cm}^{-1}$. Using the computer the detector efficiency for the above arrangement was calculated to be $q=0.08253$.

The time intervals used in the thermal flux determination are: irradiation time $t_{0}=10 \mathrm{~min}$., transfer time $t_{1}=3$ min., and counting time $t_{2}=3$ minutes.

Substituting all the appropriate values into equation (9) onc obtains

$$
\phi_{0}=1.3432 \mathrm{C} .
$$

As a specific example the thermal flux was determined at the port opening of the graphite moderator. An indium foil was placed in the beam at the port opening. It was irradiated for 10 minutes and after a transfer time of 3 minutes was counted for 3 minutes.

The total count was $2,186,263$ and the background was 4,600 . Thus, $\mathrm{C}=2,181,663$ and

$$
\phi_{0}=2.94 \times 10^{6} \mathrm{n} / \mathrm{cm}^{2}-\mathrm{sec}
$$

which is the desired measurement. 'I'he error associated with this measurement is approximately $3.5 \%$.

\section{REFERENCES}

1. R. L. Heath, Scintillation Spectrometry, Gamma-Ray. Spectrum Catalogue, AEC Research and Development Report IDO-16880-1, Appendix III, August 1964.

2. H. A. Enge, Introduction to Nuclear Physics, Addison-Wesley Publishing Company, Inc., Reading, Massachusetts, 1966.

3. "The Texas Convention on The Measurement of 14-MeV Neutron Fluxes from Accelerator," with appendix by R. L. Heath. Proceedings of the 1965 International Conference on Modern Trends in activation Analysis, College Station, Texas, April 1965.

4. C. Michael Lederer, Jack M. Hollander, Isadore Perlman, Table of Isotopes, Sixth Edition, John Wiley \& Sons, Inc., New York, 1968. 
RFP-1466 


\section{APPENDIX I}

\section{Derivation of Detector Efficiency}

The detector efficiency is a combination of the geometry factor and the absorption factor. In this derivation, the geometry factor will be derived first and then rombined in the proper way with the absorption factor. The various quantities used in the derivation are shown in Figure I-l.

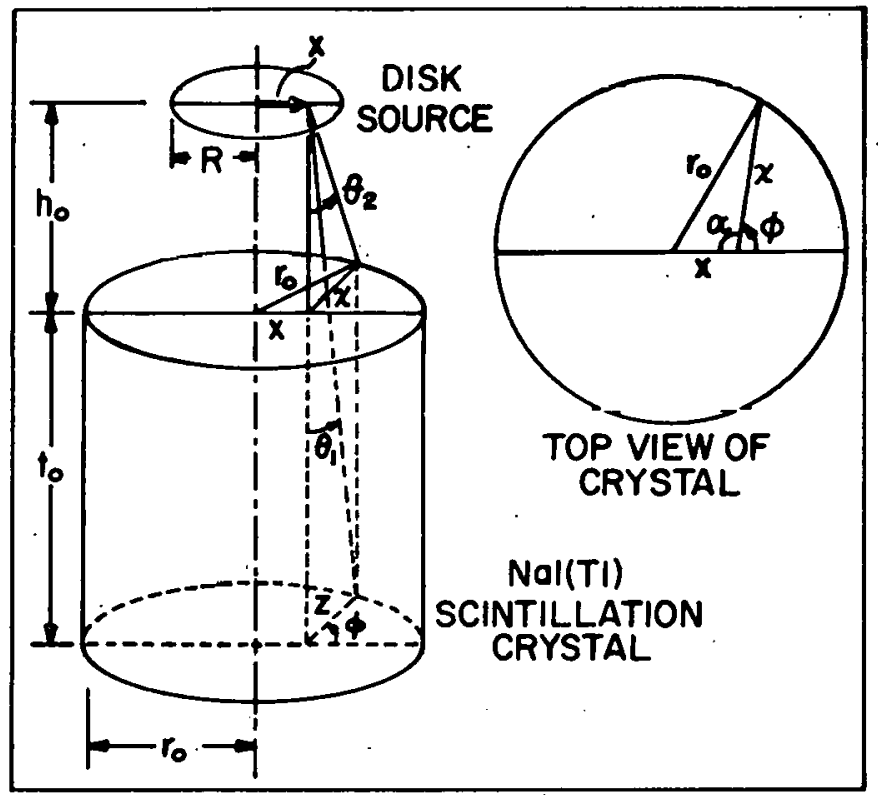

Figure I-1. Source and Detector Geometry.

The geometry factor is the solid angle subtended by the detector at the source divided by $4 \pi$. For a point source the geometry factor $G$ is given by

$$
\mathrm{G}=\frac{1}{4 \pi} \int_{0}^{2 \pi} \int_{0}^{\theta} \sin \theta \mathrm{d} \theta \mathrm{d} \phi .
$$

For a disk source of radius $\mathrm{R}$,

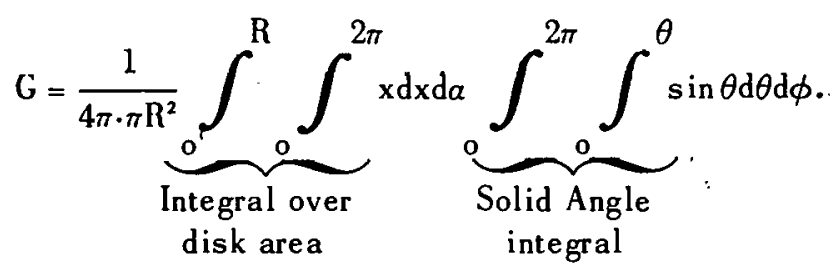

The integral over $a$ can be done immediately, and by symmetry, $\phi$ may be integrated from $n$ to $\pi$ and multiplied hy 2. Thus the above expression can be written as

$$
\mathrm{G}=\frac{1}{\pi \mathrm{R}^{2}} \int_{0}^{\mathrm{R}} \mathrm{xdx} \int_{0}^{\pi} \mathrm{d} \phi \int_{0}^{\theta} \sin \theta \mathrm{d} \theta
$$

This expression must be combined with the absorption factor, which is the ratio of photons absorbed in the crystal to the number of photons impinging on the crystal. Let $I_{0}$ be the number of photons impinging on the crystal. Then the number passing through the crystal is given by

$$
\mathrm{I}=\mathrm{I}_{0} \mathrm{e}^{-r \Psi},
$$

where $\tau$ is the absorption coefficient and $\Psi$ is the thickness of the crystal traversed by the photons. The number ahsorbed is thus

$$
\mathrm{I}_{0}-\mathrm{I}=\mathrm{I}_{0}\left(1-\mathrm{e}^{-\tau} \Psi\right)
$$

and the absorption factor is the ratio

$$
\frac{\mathrm{I}_{0}\left(1-\mathrm{e}^{-\tau \Psi}\right)}{\mathrm{I}_{0}}=\left(1-\mathrm{e}^{-\tau \Psi}\right)
$$

The detector efficiency is then given by

$q=\frac{1}{\pi R^{2}} \int_{0}^{R} x d x \int_{0}^{\pi} d \phi \int_{0}^{\theta}\left(1-e^{-\tau \Psi}\right) \sin \theta d \theta$.

The photon pathlength in the crystal $\Psi$ must be further defined in terms of the angles $\theta$ and $\phi$. Consider the top view of the crystal as shown in Figure I-l. Using the Law of Cosines,

$$
r_{0}^{2}=x^{2}+\chi^{2}-2 x \chi \cos a
$$

but

$$
\phi+a=\pi
$$

and

$$
\cos \alpha=\cos (\pi-\phi)=-\cos \phi \text {. }
$$

Thus

$$
r_{0}^{2}=x^{2}+\chi^{2}-2 x \chi \cos \phi .
$$

Rearranging terms and solving for $\chi$ by the quadratic formula gives

$$
x=-x \cos \phi+\sqrt{x^{2} \cos ^{2} \phi+r_{0}^{2}-x^{2}} .
$$


Again referring to $\mathrm{F}$ igure $1-1$, angles $\theta_{1}$ and $\theta_{2}$ are given by

$$
\theta_{1}=\tan ^{-1} \frac{x}{t_{0}+h_{0}} \text { and } \theta_{2}=\tan ^{-1} \frac{x}{h_{0}}
$$

By simple geometry then

$$
\Psi=\frac{t_{0}}{\cos \theta} \text { for } 0 \leq \theta \leq \theta_{1},
$$

and $\quad \Psi=\frac{\chi^{\prime}}{\sin \theta}-\frac{\mathrm{h}_{\mathrm{u}}}{\cos \theta}$ for $\hat{\theta}_{1}^{\prime} \leq \theta \leq \theta_{2}$.

Substituting these values for $\Psi$ into the expression for the detector efficiency gives

$$
\begin{aligned}
\mathrm{q}= & \frac{1}{\pi \mathrm{R}^{2}} \int_{0}^{\mathrm{R}} \mathrm{xd} \mathbf{x} \cdot \int_{0}^{\pi} \mathrm{d} \phi\left\{\int_{0}^{\theta_{1}}\left(1-\mathrm{e}^{-\tau \cdot \mathrm{t}_{0} / \cos \theta}\right) \sin \theta \mathrm{d} \theta\right. \\
& \left.+\int_{\theta_{1}}^{\theta_{2}}\left[1-\mathrm{e}^{-\tau}\left(\chi / \sin \theta-\mathrm{h}_{0} / \cos \theta\right)\right] \sin \theta \mathrm{d} \theta\right\} .
\end{aligned}
$$

Vegors et al.,' uses a slightly different form of the above equation. The principle axis for the angle $\phi$ is shown in Figure I-2. By the Law of Cosines'

$$
r_{0}^{2}=x^{2}+x^{2}-2 x x \cos a
$$

But $\quad \phi+a=\frac{3 \bar{\pi}}{2}$

so

$$
\begin{aligned}
\cos a & =\cos \pi-(\phi-\pi / 2)=-\cos (\phi-\pi / 2) \\
& =-\cos (\pi / 2-\phi)=-\sin \phi .
\end{aligned}
$$

Thus $\quad r_{0}^{2}=x^{2}+\chi^{2}+2 x \chi \sin \phi$.

Solving for $\chi$ gives

$$
x=-x \sin \phi+\sqrt{x^{2} \sin ^{2} \phi+r_{0}^{2}-x^{2}}
$$

Now in order to preserve symmetry the integral over $\phi$ must go from $-\pi / 2$ to $\pi / 2$ or from $\pi / 2$ to $\pi$.

\footnotetext{
${ }^{1}$ S. H. Vegors et al., Calculated Efficiencies of Cylindrical Radiation Detectors, AEC Report IDO-16370 (1958).
}

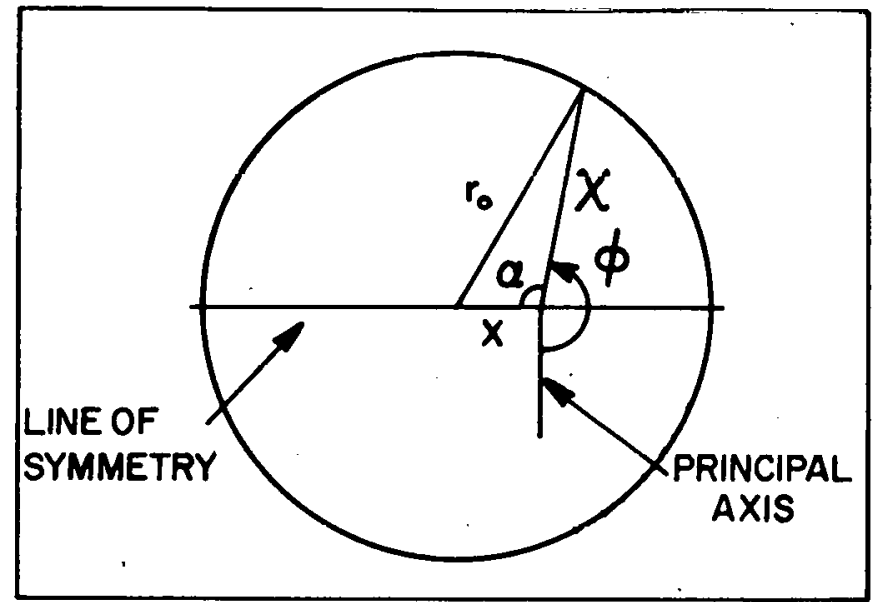

Figure 1-2. Top View of Crystal Showing Heath's Modification.

If the source is thick then the expression for the geometry factor is extended to include the thickness and is given hy

$$
\mathrm{G}^{2}=\frac{1}{4 \pi \cdot \pi \mathrm{R}^{2} \cdot \mathrm{t}} \underbrace{\int_{0}^{\mathrm{t}}}_{\substack{\text { integral over } \\
\text { diols volume }}} \underbrace{\mathrm{R}}_{\begin{array}{c}
\text { solid angle } \\
\text { integral }
\end{array}}
$$

$\sin \theta \mathrm{d} \theta \mathrm{d} \phi$

The development of this expression is identical to that given above. Thus, the final expression for a source of thickness $t$ is

$q=\frac{1}{\pi R^{2} t} \int_{0}^{t} d y, \int_{0}^{R} x d x \int_{0}^{\pi} d \phi$

$$
\begin{aligned}
& \int_{0} \int_{\theta_{1}}^{\theta}\left(1-e^{-\tau t_{0} / \cos \theta}\right) \sin 0 d \theta \\
& \left.+\int^{\theta_{2}}\left[1-e^{-\tau}(\chi / \sin \theta-h / \cos \theta)\right] \sin \theta d \theta\right\}
\end{aligned}
$$

where $h=h_{0}+y$ and all other variables are defined as before. 


\title{
APPENDIX II
}

\section{Computer Program for Calculation Of Detector efficiency}

\begin{abstract}
OC EFFIC--A PROGRAM TO CALCULATE THE DETECTOR EFFICIENCY OF A
1C SODIUM IODIDE CRYSTAL. RO IS THE RADIUS OF THE DETECTOR, $R$

$2 C$ IS THE RADIUS OF THE DISK SOURCE, HO IS THE DISTANCE FROM

3C THE SOURCE TO THE DETECTOR, TO IS THE THICKNESS OF THE

$4 \mathrm{C}$ DETECTOR, AND TAU IS THE ABSORPTION COEFFICIENT OF THE NAI(TL)

5C CRYSTAL AND IS ENERGY DEPENDENT. T IS THE SOURCE THICKNESS.
\end{abstract}

$6 \mathrm{C}$

$7 \mathrm{C}$

1 OOC NUMERICAL INTEGRATION OF NAI(TL) DETECTOR EFFICIENCY

$110 \mathrm{C}$

120 DIMENSION CONST(25)

130 PRINT 40,

140 PRINT 50,

150 PRINT,

160 CALL OPENF (1, "EFFICD")

$170 \operatorname{READ}(1,) \mathrm{N}$

180 DO $1 \cap 0 \quad I P \equiv 1, \mathrm{~N}$

190 READ (1,) RO, TO, R, T, HO, TAU

$200 M=19$

$210 \operatorname{IF}(T \cdot E Q \cdot 0 \cdot 0) M=1$

$220 \operatorname{CONST}(1)=1.0$

$230 \operatorname{consT}(2)=5.0$

$240 \operatorname{CONST}(3)=1.0$

$250 \operatorname{ConsT}(4)=6.0$

$260 \operatorname{CONST}(5)=1.0$

$270 \operatorname{CONST}(6)=5.0$

$280 \operatorname{CONST}(7)=2.0$

$290 \operatorname{CONST}(8)=5.0$

$300 \operatorname{CONST}(9)=1.0$

$310 \operatorname{CONST}(10)=6.0$

$320 \operatorname{ConsT}(11)=1.0$

$330 \operatorname{ConST}(12)=5.0$

$340 \operatorname{ConsT}(13)=2.0$

$350 \operatorname{CONST}(14)=5.0$

360 CONST $(15)=1.0$

$370 \operatorname{CONST}(16)=6.0$

$380 \operatorname{CONST}(17)=1.0$

$3,90 \operatorname{CONST}(18)=5.0$

$400 \operatorname{CONST}(19)=1.0$

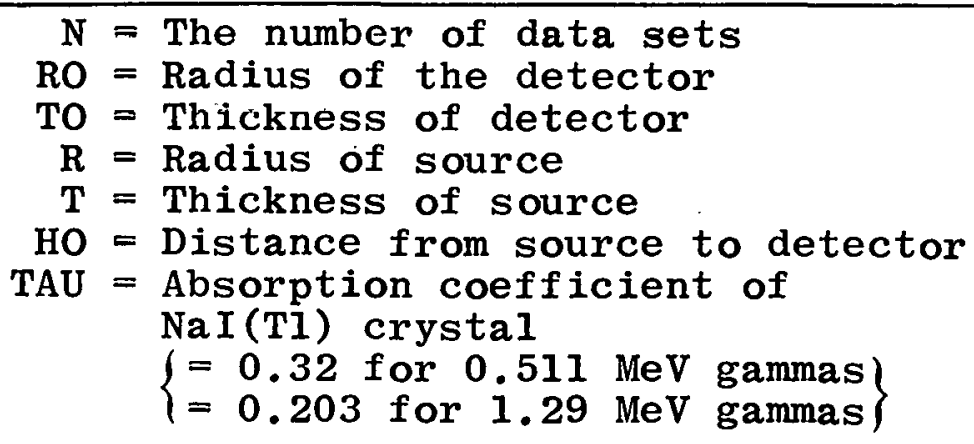

All values of the input data must be in centimeters. The output data is in inches. The input data is stored under the file name "EFF ICD".

$410 P I=3.1415926536$

420 TOTINT $=0.0$

430 DO $35 \mathrm{~L}=1, \mathrm{~N}$

$440 \mathrm{AL}=\mathrm{L}$

$450 Y=(A L-1.0) *(T / 18.0)$

$460 \mathrm{H}=\mathrm{HO}+\mathrm{Y}$

470 RINT $=0.0$

480 DO $30 \quad I=1,19$

$490 \mathrm{AI}=\mathrm{I}$

$500 X=(A I-1.0) *(H / 18.0)$

510 PHIINT $=0.0$

520 DO $20 \quad J=1,19$ 
RFP-1466

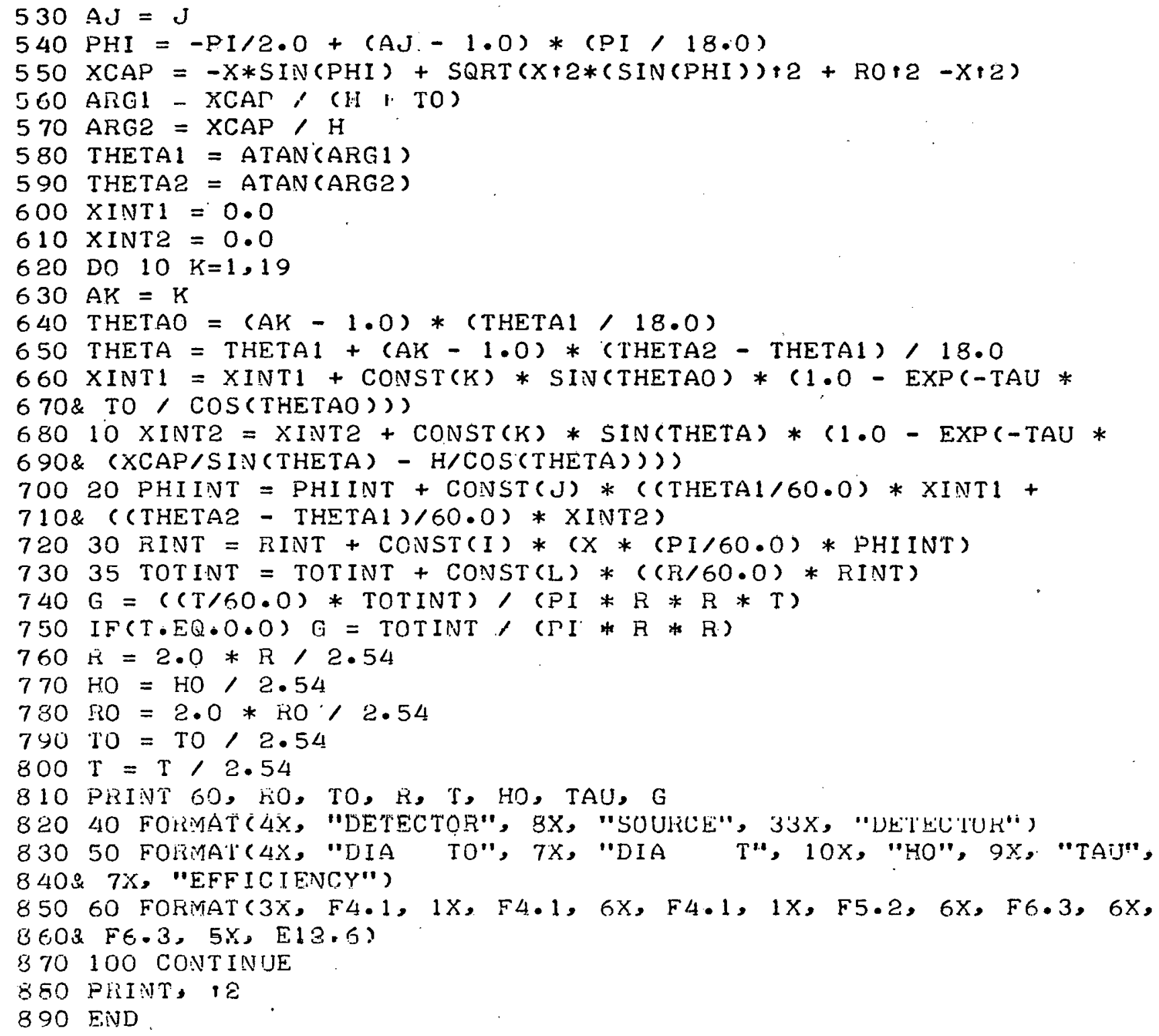

1002

$1103.81,7.62,1.27,1.905,2.0475,0.32$

$\leftarrow$ INPUT

$1203.81,7.62,1.27,0.0,3.0,0.203$

DETECTOP

SQITRCF.

DIA TO

DIA T

HO

TAO

DEIECTOR

OUtput

$3.0 \quad 3.0$

$1.0 \quad 0.75$

0.306

0.32 .0

EFFICIENCY

$3.0 \quad 3.0$

$1.0 \quad 0.00$

1.181

0.203

$0.107499 E+00$

$0.825311 \mathrm{E}-01$ 